\title{
NEUTRALITY IN MEDIATION: AN AMBIGUOUS ETHICAL VALUE
}

\section{Paul Bailey}

\section{Abstract}

Mediator neutrality would appear, by definition, to be a necessary and required ethical principle for all mediators to practice. But what is meant by neutrality in mediation? Is it practically possible to be completely neutral between parties in mediation while at the same time being fair to both of them? This paper attempts to answer these two questions.

\section{Keywords}

Neutrality, mediation, ethical value

\section{Literature Review}

A review of the literature on mediator neutrality reveals differing conceptualisations of the issue. Some commentators synonymise neutrality with impartiality while others view impartiality as a quality or a conception of neutrality. Moore (2003) distinguishes between the two. He views impartiality as referring "to the absence of bias or preference in favour of one or more negotiators, their interests, or the specific solutions that they are advocating" (Moore, 2003: 53). Neutrality is seen by Moore as referring "to the relationship or behaviours between intervener and disputants" (Moore, 2003: 53). His emphasis here is on the mediator not having had any previous relationship with the disputing parties from which the mediator "could directly and significantly benefit". Moore sums up the distinction when he states "when acting as an independent mediator, the intermediary should explain that she is impartial in her views and neutral in her relationship to the parties" (Moore, 2003:215). Failure, on the part of the mediator, to properly explain this distinction... "can result in grievances against mediators" (Maiese, 2005).

In contrast, Rifkin et al (1991:152), view impartiality as one of the two qualities of neutrality, the other being equidistance. They define impartiality as "the ability of the mediator (interventionist) to maintain an unbiased relationship with the disputants". Equidistance refers to "those practices by which mediators support or encourage the disclosure of the disputants". Rifkin et al (1991) note that "to ensure that information is disclosed, the mediator must temporarily align herself or himself with individual parties as they elaborate their position". Of particular note is that the authors see impartiality and equidistance as "contradictory by definition" (Rifkin et al., 1991:153) which they believe can lead to difficulties for mediators when trying to practice both concepts in a mediation session. To counteract this, they propose an alternative "discourse of storytelling" where mediators become "managers of the 
storytelling process" (Rifkin et al., 1991: 161). The authors argue that "the discourse of storytelling will enable both mediators and scholars to better understand the process of mediation and escape the paradox of neutrality as well" (Rifkin et al., 1991:162). This notion of "paradox" is strongly refuted however, by Feer (1992) who views equidistance as "a tool used at the discretion of the practitioner" and "not as an element defining neutrality" (Freer, 1992:174).

Cobb (1993) defines mediation as "a set of discursive practices that enhance the participation of disputants" (Cobb, 2000:142). Such practices, she argues allow participants to build a "conjoint story" and enables them to construct "positive positions for themselves" (Cobb, 2000:142). As such, Dyck (2000) states that "Cobb challenges the notion of mediator neutrality and suggests that the intervener always influences the content in a dispute" (Dyck, 2000:142). Agreeing with Cobb, Cloke (2001) holds that "there is no such thing as genuine neutrality when it comes to conflict. Everyone has had conflict experiences that have shifted his or her perceptions, attitudes, and expectations, and it is precisely these experiences that give us the ability to empathise with the experiences of others", (Cloke, 2001:12). He develops this point further by observing "the language of neutrality creates an expectation that mediators will act fairly once they erase their own past experiences. But real fairness comes from using the past to gain an open, honest, humble perspective on the present" (Cloke, 2001:13). Cloke (2001) also says of neutrality "it can fail to comprehend spirit, forgiveness, transformation or healing, which are essential in mediation. As a result, it can become a straitjacket and a check on our ability to unravel the sources of conflict" (Cloke, 2001:14). Dyck, (2000) in his comparative analysis of mediation and nonviolent advocacy, also rejects the notion of mediator neutrality as the guiding principle of conduct in mediation accepting that "the mediator does influence the content of the dispute" particularly when there is a reluctance of the parties to "participate toward the creation of a conjoint narrative" (Dyck, 2000: 143). Similarly, Mayer (2004) notes:

“........people often do not trust our neutrality. They are suspicious of the concept and question, often correctly, whether we can genuinely be as neutral, impartial, and unbiased as we say we are. Most important perhaps, neutrality is not what people embroiled in deep conflict are usually looking for. They want assistance, advocacy, advice, power, resources, connections, or wisdom. We tend to rely heavily on a neutral stance to obtain trust and credibility, whereas disputants are more inclined to accept the procedural help of a non-natural who brings other resources to bear and to doubt the practical usefulness of someone who is genuinely neutral" (Mayer, 2004:17).

Mediator neutrality is particularly called into question where there is a clear power imbalance between parties in a dispute. Moore (2003) refers to this as "asymmetrical power". He notes that "mediators can work with both weaker and stronger parties to minimise the negative effects of unequal power" (Moore, 2003:391). Mayer (2003) suggests some empowering moves as follows:

- Assisting a person in mediation in obtaining, organising, and analysing data and identifying and mobilising his or her means of influence. 
- Assisting and educating a person in mediation in planning an effective negotiation strategy.

- Aiding a person in mediation in developing financial resources so that he or she can continue to participate in negotiations.

- Referring a person in mediation to a lawyer or other resource.

- Encouraging the party to make realistic concessions. (Mayer, 2003:392-393)

In preparing a person in mediation in this way, the mediator is contributing towards a more "productive exchange that will benefit both parties" (Mayer, 2003: 393). Hansen (1999), speaking on power imbalance in his work with the Community Relations Service states:

...unless I can help balance that, and empower each party to effectively participate at the mediation table, we're not going to have an effective, successful mediation. So I explain that to the institution and I offer pre-mediation training to both sides. I also use that as ways to help each of the parties identify what their interests and concerns are, and what they hope to get out of this process. (Hansen, 1999)

What Hansen is describing here is what Benjamin (1998) calls "balanced" mediation. He notes, "in contrast to the more static neutral mediator, who has no responsibility to protect either party, a balanced mediator has the responsibility to protect both parties. In being balanced, the mediator has permission to question both parties about their negotiating perspectives and inquire about any circumstance or matter germane to an effective, resilient agreement" (Benjamin, 1998).

It would appear from this brief review of the literature on neutrality that there is a challenge for mediators in finding a balance between neutrality and empowering the parties to engage in a process that fully addresses both their needs. As Taylor (1997) observes, "If mediators are too tightly bound by procedural requirements for scrupulously neutral process they will lose the ability to fashion a process that truly addresses the needs (substantive and procedural) of clients. Equally if mediators start muscling clients into positions they do not wish to take or prevent them from making agreements they freely chose, this may no longer be a neutral process" (Taylor,1997:222).

The literature reviewed above supports the view that neutrality in mediation is impossible to practice if the mediator is to be fair to both parties in the process to enable them to reach agreement on their issues in dispute. The key skill lies in knowing when and how to intervene without compromising the entire process. Such a skill is "the hallmark of a reflective and competent practitioner" (Taylor, 1997:222).

Kenneth Cloke (2001) sums up the argument with his usual eloquence when he states, "in mediation, there is no judge, no power to decide in anyone other than the parties, no process other than consensus, and no victory other than a rough equality of loss. Both sides have the right to veto any outcome they perceive as unequal. For this reason, it is not neutrality that is important, but the ability to reach out, use subjectivity, and deepen empathy and honesty between adversaries" (Cloke, 2001:12-14). 


\section{References}

Benjamin, R. (1998) The Risks of Neutrality - Reconsidering the Term and Concept [online], Mediate.com, available from http://www.mediate.com/articles/benjamin.cfm [Accessed 10th December 2011]

Cloke, K. (2001) Mediating Dangerously - The Frontiers of Conflict Resolution. San Francisco: Jossey-Bass Cobb.

S. "Empowerment and Mediation: A Narrative Perspective." Negotiation Journal. 1993, 9

(3), 245-259.

Dyck, D. (2000) 'The Mediator as Nonviolent Advocate: Revisiting the Question of Mediator Neutrality', Mediation Quarterly, 18 (2): 129-149

Feer, M. (1992) 'On "Toward a New Discourse for Mediation: A Critique of Neutrality", Mediation Quarterly, 10 (2): 173-177

Hansen, S. (1999) --Silke Hansen interview from the Civil Rights Mediation Oral History Project. Available online at http://www.colorado.edu/conflict/civil_rights/interviews/Silke_Hansen.html (Accessed 10th December 2011]

Maiese, M. (2005) Neutrality [online], Beyond Intractability, Available from http://www.beyondintractability.org/bi-essay/neutrality [Accessed 1stDecember 2011]

Mayer, B. (2004) Beyond Neutrality: Confronting the Crisis in Conflict Resolution, San Francisco: Josey-Bass

Moore, C. (2003) The Mediation Process - Practical Strategies for Resolving Conflict (3rd Edition), San Francisco: Jossey-Bass

Rifkin, J., Millen, J. and Cobb, S. (1991) 'Toward a New Discourse for Mediation: A Critique of Neutrality',

Mediation Quarterly, 9 (2): 151-164

Taylor, A. (1997) 'Concepts of Neutrality in Family Mediation: Contexts, Ethics, Influence, and Transformative Process', Mediation Quarterly, 14 (3): 215-236

Paul Bailey is an accredited mediator and is a graduate of the Masters Programme in Mediation \& Conflict Intervention at NUI Maynooth. Paul began his career as a Social Care Worker before going on to manage a number of services for marginalised young people. In 2001, he became the first Executive Director of the Child Protection Office of the Irish Bishops' Conference, the predecessor to the National Board for Safeguarding Children in the Catholic Church in Ireland. Paul's other appointments include Head of Communication, Ombudsman for Children's Office; Director, BOND, Blanchardstown; Employee Relations Manager, FÁS, during which time he conducted several workplace mediations. His current role is in the Press \& Communications Office of the Department of Health. Paul has particular interests in victim offender mediation and organisational and workplace mediation. 